\title{
Corrosion Resistance Evaluation of Some Stainless Steels Used in Manufacture of Hydraulic Turbine Runner Blades
}

\author{
CRISTIAN PREDESCUㄹ, ANDREI CONSTANTIN BERBECARU ${ }^{1}$, GEORGE COMAN ${ }^{1}$, MIRELA GABRIELA SOHACIU ${ }^{1}$,

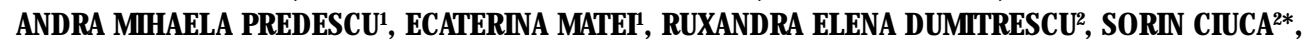 \\ IOANA ARINA GHERGHESCU²* \\ 'POLITEHNICA University of Bucharest, Materials Science and Engineering Faculty, Department of Metallic Materials Processing \\ and Eco - Metallurgy , 313 Splaiul Independenkei, 060042, Bucharest, Romania \\ 2POLITEHNICA University of Bucharest, Materials Science and Engineering Faculty, Department of Materials Science and \\ Physical Metallurgy, 313 Splaiul Independenæei, 060042 Bucharest, Romania
}

\begin{abstract}
The paper presents corrosion resistance testing results of three stainless steels that may be used in hydropower turbine blades manufacture. Two of these have a chemical composition close to that of some other stainless steels previously employed in producing these parts, being updated steel grades of the former ones. The third one is of a new conception, having a chemical composition close to that of a maraging steel. The three materials were produced in an induction furnace with cold copper crucible under vacuum and argon atmosphere in order to obtain improved mechanical and corrosion resistance characteristics as well as an inclusion - free structure. Quenching and tempering heat treatments were subsequently applied. Tests were carried out at room temperature in normally aerated $1 \mathrm{~N} \mathrm{Na}_{2} \mathrm{SO}_{4}$ and $3 \% \mathrm{NaCl}$ solutions. Corrosion rates were calculated using the Tafel slope method. All steels have a passivation tendency in a chlorine-free aqueous medium. The newly conceived steel has a more pronounced anodic field as a result of a chromium content below $12 \%$. However, the general corrosion behavior of this material is rebalanced by the content of about $10 \% \mathrm{Ni}$ which leads to a mainly martensitic structure in quenched state. The corrosion rate values obtained for all samples enframe the three materials in highly and very highly corrosion resistantsteels. Nevertheless it must be specified that in chlorine environments the overall corrosion rate is not a sensitive indicator of corrosion resistance performance due to the local depassivation process followed by corrosion pits.
\end{abstract}

Key words: corrosion resistance, turbine runner blade, new martensitic steel, maraging steel

The main aggregate of hydropower plants is the turbine, the blade runner being its most important device. Parts such as runner blades may be subjected to premature failure. Several problems related to them were identified in hydroelectric power plants on the river Olt, Romania.

Corrosion is one of the possible degradation causes of the runner blade assembly besides cavitation wear, abrasion wear, fatigue and material defects. It leads to increasing the mending durations as a consequence of runner blades cracks occurrence. The materials used in manufacturing hydropower runner blades are stainless steels.

Pitting corrosion may occur when it comes to stainless steel parts. It is initiated by physical or chemical heterogeneity at the metallic surface, such as inclusions, segregation at grain boundaries, defects, mechanical damage or dislocations [1].

Among physical factors influencing pitting corrosion, temperature, environment $\mathrm{pH}$, salinity can be mentioned. Some chemical factors are a high concentration of chlorine ions or a high content of dissolved oxigen in water as working environment.

If a material is defect - free, pitting corrosion is caused by the environment that may contain aggressive chemical elements. For instance chloride damages the oxide passive film and pitting can begin at the place where the oxide layer breaks. In a chemically mild environment, pitting is caused by the material inclusions, $\mathrm{MnS}$ being often responsible for it [1 - 3].
The choice between the two main stainless steel classes, austenitic and martensitic, is based on the need to confer a high enough hardness to withstand the impact of the water filled with particulates and a good corrosion resistance to the runner blades.

Martensitic steels are usually chosen but the corrosion resistance is not high enough $[4,5]$. Nickel addition and a low carbon content leads to a high hardness of the runner blade material confered by a structure containing uniformly distributed precipitates, by increasing the weldability.

Austenitic steels are better materials in terms of corrosion resistance, weldability, plasticity and creep resistance but they have weaker mechanical properties. An enhancement of the latter is given by a partial substitution of Ni with $\mathrm{Mn}$ and $\mathrm{N}$, with a corrosion resistance decline.

Better structural characteristics of commonly chosen stainless steels are expected to be found when steel making is performed in an induction funace with cold copper crucible, leading to an improved electrochemical behavior.

Three stainless steels were chosen for an electrochemical corrosion study in this work. The chemical compositions of the first two materials are improved compositions of usually steels used to that effect. Moreover, efforts have been made to conceive a new stainless steel for hydropower turbines, also made in an induction furnace with cold crucible. This choice concerning the steel making method could eliminate all drawbacks induced by a defective casting structure. 


\section{Experimental part}

Steels were made in an induction furnace with a cold copper crucible with an inner diameter of $35 \mathrm{~mm}$ and a capacity of $8-15 \mathrm{~cm}^{3}$ equipped with a casting plug. The working parameters of the furnace are: nominal power 25 $\mathrm{kW}$, frequency HF $100-400 \mathrm{kHz}$, apparent power $40 \mathrm{kVA}$, phase current $40 \mathrm{~A}$, power factor 0.92 , minimum water flow $12 \mathrm{l} / \mathrm{min}$, maximum inlet pressure: $7.5 \mathrm{bar}$, water inlet: max. $24^{\circ} \mathrm{C}$, maximum working temperature of $2800^{\circ} \mathrm{C}$.

Two formerly stainless steels used in manufacturing runner blades for hydropower turbines located on river Olt, Romania, were T8NCUMC130CS L03.009.0 and GX4CrNi134 (EN 10283). Their chemical compositions determined by optical spectroscopy were presented in table 1,2 .

These chemical compositions were also improved and are found in table 3 as P1 and P2 steels, respectively. For P1 steel, Ni content was raised from 1.325 to $4.34 \%$ and the $\mathrm{Cr}$ one was lowered from 13.453 to $11.78 \%$. Other changes were made in order to reach a compromise between the mechanical characteristics and the corrosion resistance behavior of these materials. Copper was not presentin the new chemical compositions. Despite its good influence on the corrosion resistance, the mechanical properties are negatively affected.

The chemical composition of the new P3 steel was established in order to obtain a more resistantsteel, suitable to fill the complex requests of hydropower turbine different parts.

Three steel ingots with the chemical composition shown in Table 3 were obtained. P1 and P2 steels have a martensitic -ferritic structure and P3 a martensiticaustenitic one, according to Schaeffler diagram [6].

In P3 steel, small amounts of Ti ( $0.92 w t \%)$, were added [7]. Its chemical composition is close to that of maraging steels, with which it is related. In maraging steels $\mathrm{Ti}$ is present because it favors the precipitation of $\mathrm{Ni}_{3} \mathrm{Ti}$ compounds which generate the highest hardening effect $[8,9]$.

A Ti addition is needed because it activates the formation of $\mathrm{Ni}_{3} \mathrm{Mo}$ compound, which somewhat lowers the hardness but does not weakens much the corrosion resistance. Precipitation consists in the mixed $\mathrm{Ni}_{3}(\mathrm{Ti}, \mathrm{Mo})$ compound $[8,9]$. Ti should be added in a small quantity because the hardening mechanism induces high internal stresses on the crystalline level, which could negatively influence the corrosion resistance of the new designed steel.

Considering all these data, a minimum concentration of $\sim 0.9$ wt\% Ti was added. Three batches, P1, P2, P3, were obtained, with the chemical compositions presented in table 3.

Samples obtained from P1, P2 and P3 steels will be thus termed samples 1,2 and 3. These were afterwards submitted to the following heat treatments (table 4).

The corrosion resistance was determined by the Tafel technique. Tafel plots allow the direct measurement of the corrosion current from which the corrosion rate can be quickly calculated.

In order to estimate the corrosion resistance of the tested samples, the following parameters were determined from the Tafel curves: the corrosion potential $\left(\mathrm{E}_{\mathrm{cor}}\right)$, the corrosion current density $\left(\mathrm{i}_{\text {corr }}\right)$, the cathodic curve slope - Tafel constant $\beta$, the anodic curve slope - Tafel constant $\beta$.

Their values allowed the evaluation of the corrosion rate (CR), parameter that describes the corrosion resistance of the tested samples.

The formula for computing the corrosion rate, according to ASTM G102-89 (2004), is the following:

$$
C R=K_{i} \cdot \frac{i_{\text {corr }}}{\rho} \cdot E W
$$

where: $C R$ is the corrosion rate $(\mathrm{mm} / \mathrm{y}), \mathrm{K}_{\mathrm{i}}$ is a constant, $3.27 \times 10^{-3}, \rho$ is the alloy density $\left(\mathrm{g} / \mathrm{cm}^{3}\right), i_{\text {corr }}$ is the corrosion current density $\left(\mu \mathrm{A} / \mathrm{cm}^{2}\right)$ and $\mathrm{EW}$ the equivalent weight (g) $[10,11]$.

The equipment used to analyse the steels corrosion behavior was Gamry Reference 600 potentiostat/ galvanostat with data analysis specialized software Echem Analisys. Tests were carried out at room temperature $\left(22^{\circ} \mathrm{C}\right)$ in freshly prepared solutions of $1 \mathrm{~N} \mathrm{Na}_{2} \mathrm{SO}_{4}$ and $3 \%$

Table 1

CHEMICAL COMPOSITION OF RUNNER BLADE STEEL NO.1 (FACTORY STEEL GRADE)

\begin{tabular}{|l|c|c|c|c|c|c|c|c|c|c|}
\hline \multirow{2}{*}{$\begin{array}{c}\text { Factory steel } \\
\text { grade }\end{array}$} & \multicolumn{10}{|c|}{ Content, wt \% } \\
\cline { 2 - 12 } & $\mathrm{C}$ & $\mathrm{Si}$ & $\mathrm{Mn}$ & $\mathrm{P}$ & $\mathrm{S}$ & $\mathrm{Cr}$ & $\mathrm{Ni}$ & $\mathrm{Mo}$ & $\mathrm{Cu}$ & $\mathrm{V}$ \\
\hline Runner blade 1 & 0.074 & 0.332 & 0.595 & 0.016 & 0.022 & 13.453 & 1.325 & 0.066 & 1.295 & 0.029 \\
\hline T8NCuMC130 CS & $\max$. & $\max$. & $0.2 \div$ & $\max$ & $\max$ & $12.0 \div$ & $1.0 \div$ & & $1.0 \div$ & - \\
L03.009.0 & 0.10 & 0.4 & 0.6 & 0.025 & 0.030 & 13.5 & 1.5 & - & 1.3 & - \\
\hline
\end{tabular}

Table 2

CHEMICAL COMPOSITION OF RUNNER BLADE STEEL NO.2 (FACTORY STEEL GRADE)

\begin{tabular}{|c|c|c|c|c|c|c|c|c|c|c|c|}
\hline \multirow{2}{*}{$\begin{array}{c}\text { Factory steel } \\
\text { grade }\end{array}$} & \multicolumn{10}{|c|}{ Content, wt \% } \\
\cline { 2 - 12 } & $\mathrm{C}$ & $\mathrm{Si}$ & $\mathrm{Mn}$ & $\mathrm{P}$ & $\mathrm{S}$ & $\mathrm{Cr}$ & $\mathrm{Mo}$ & $\mathrm{Ni}$ & $\mathrm{V}$ & $\mathrm{A} 1$ & $\mathrm{Cu}$ \\
\hline $\begin{array}{c}\text { Runner blade } \\
2\end{array}$ & 0.025 & 0.40 & 0.73 & 0.035 & 0.002 & 12.60 & 0.35 & 3.82 & 0.03 & 0.012 & 0.35 \\
\hline $\begin{array}{c}\text { G-X4CrNi13- } \\
4\end{array}$ & $<0.06$ & $<1$ & $<1$ & $<0.035$ & $<0.025$ & $\begin{array}{c}12- \\
13.5\end{array}$ & $\begin{array}{c}0.4- \\
1\end{array}$ & $\begin{array}{c}3.5- \\
4.5\end{array}$ & - & - & - \\
\hline
\end{tabular}

Table 3

CHEMICAL COMPOSITIONS IN WT\% OF P1, P2 AND P3 STEELS

\begin{tabular}{|c|c|c|c|c|c|c|c|c|c|c|c|c|c|c|c|}
\hline & $\mathrm{Cr}$ & $\mathrm{Ni}$ & Mo & $\mathrm{Si}$ & $\mathrm{Cu}$ & Mn & $\mathrm{Ti}$ & Al & $\mathbf{N b}$ & $\mathrm{C}$ & $V$ & $\mathrm{Co}$ & $\mathbf{P}$ & $\mathbf{S}$ & $\mathrm{Fe}$ \\
\hline P1 & 11.78 & 4.34 & 0.002 & 0.182 & 0.078 & 0.550 & 0.001 & 0.0061 & 0.012 & 0.042 & 0.025 & 0.016 & 0.0079 & 0.0085 & 82.95 \\
\hline $\mathrm{p}_{2}$ & 12.05 & 3.85 & 1.024 & 0.393 & 0.170 & 0.676 & 0 & 0.0282 & 0.0438 & 0.0426 & 0.0081 & 0.0299 & 0.0287 & 0.0114 & 81.64 \\
\hline P3 & 9.92 & 9.61 & 5.07 & 0.295 & 0.147 & 0.351 & 0.923 & 0.049 & 0.0889 & 0.0223 & 0.0022 & 0.0356 & 0.0204 & 0.0204 & 73.8 \\
\hline
\end{tabular}

\begin{tabular}{|c|c|c|}
\hline & Quenching temperature, ${ }^{\circ} \mathrm{C}$ & Tempering (ageing) temperature, ${ }^{\circ} \mathrm{C}$ \\
\hline P1 & 1000 & 700 \\
\hline P2 & 1000 & 700 \\
\hline P3 & 1000 & 480 \\
\hline
\end{tabular}

Table 4

TEMPERATURES OF HEAT TREATMENTS PERFORMED ON THE THREE STEELS 


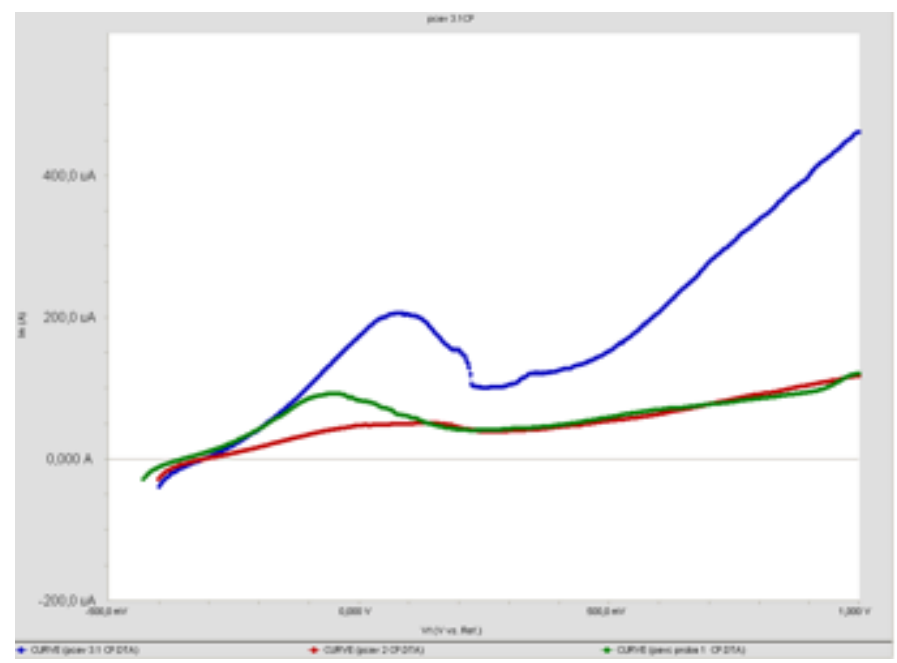

Fig.1 Anodic polarization curves of the three samples tested in $1 \mathrm{~N}$ $\mathrm{Na}_{2} \mathrm{SO}_{4}$ solution at room temperature with a polarization rate of $1 \mathrm{mV} / \mathrm{s}$

$\mathrm{NaCl}$, normally aerated. Calculation of corrosion rates was performed using the Tafel slope method.

\section{Results and discussions}

Electrochemical corrosion behavior in aqueous media of $P 1, P 2$ and $P 3$ steels

The polarization curves of the three steels tested in the chlorine-free aqueous medium (which is the working environment of the hydropower turbines) are shown in figure 1 and the polarization curves of the three steels tested in the aqueous chlorine medium are shown in figure 4.

From the analysis of the anodic polarization curves shown in figure 1, the following aspects emerge: all steels exhibit a passivation tendency in the chlorine-free aqueous medium, with the specification that steel P3 has a more pronounced anodic range, due to its chromium content below $12 \%$ which is the lower limit for a stainless steel. The general corrosion behavior of this material is counterbalanced by the content of about 10\% Ni which gives a structure positioned mainly in the martensitic domain subsequent to a quenching heat treatment. One should note that values of current densities are of the order of $\mu \mathrm{A} / \mathrm{cm}^{2}$ for all materials, those for the field of active dissolution included (maximum peak of each curve) even though we can not talk about proper surface passivation. Figure 2 and table 5 show the results of Tafel curves analysis.

Figure 2 shows that steels $\mathrm{P} 2$ and $\mathrm{P} 3$ have virtually the same corrosion potential of about $50 \mathrm{mV}$ more electropositive than the P1 one, indicating an increased passivation tendency.

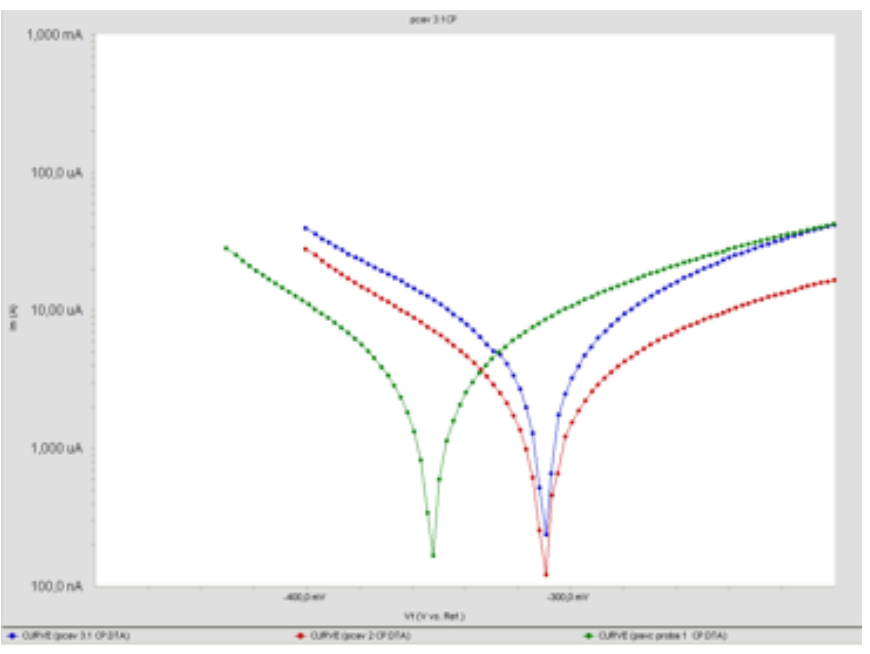

Fig. 2. Tafel curves for P1, P2, P3 steels in $1 \mathrm{~N} \mathrm{Na}_{2} \mathrm{SO}_{4}$ solution

The corrosion rate of $3.654 \mathrm{mpy}(0.0928 \mathrm{~mm} /$ year $)$ enframes the P3 material as corrosion resistant according to the norms.

One may note that from this point of view all 3 materials fall into the same corrosion resistance class, with corrosion rate differences of the order of $1.5 \mathrm{mpy}$.

SEM analysis of samples submitted to corrosion did not reveal any alteration of the surface, as seen in Figure 3.

Considering that there are no significant differences between the three materials in respect of their corrosion behavior, they were submitted to much tougher conditions, namely $3 \%$ sodium chloride solution (it simulates sea water).

Analysis of the materials behavior in $3 \% \mathrm{NaCl}$ solution is shown in (figs. 4 - 5 and table 6).

The increased aggressiveness of the testing medium and the high amount of chlorine ions prevents surfaces passivation. Basically the corrosion current is continuously increasing reaching relatively high values of the $\mathrm{mA} / \mathrm{cm}^{2}$ order, the polarization curves sharply change the Di/Du slope to more electronegative potential values when compared to the previous medium (sulfate). Between steels P2 and P3 the differences are insignificant. The polarization curves overlap over a relatively broad range of potential.

Regarding the corrosion rate values, all three steels are enclosed in very resistant - resistant grades, indicating that in chlorine environments the overall corrosion rate is not an indicator of the corrosion resistance performance due to the local depassivation process, leading to corrosion pits seen in the SEM images, (fig. 3).

Samples 1 and 2 show ed large scale attacks of the order of millimeters in length that seem to follow a preferential

Table 5

MAIN PARAMETERES OF THE CORROSION PROCESS IN IN NA $\mathrm{SO}_{4}$ SOLUTION

\begin{tabular}{|l|c|c|c|c|c|c|}
\hline & $\beta_{2}, \mathrm{~V} /$ decade & $\beta_{\varepsilon}, \mathrm{V} /$ decade & $\mathrm{i}_{\text {corr }, \mu \mathrm{A} / \mathrm{cm}^{2}}$ & $\mathrm{E}_{\text {cor }}, \mathrm{mV}$ & $\mathrm{CR}, \mathrm{mpy}$ & $\mathrm{CR}, \mathrm{mm} / \mathrm{y}$ \\
\hline P1 & $256.2 \times 10^{-3}$ & $199.6 \times 10^{-3}$ & 10.4 & -353.0 & 5.127 & 0.1302 \\
\hline P2 & $177.7 \times 10^{-3}$ & $125.6 \times 10^{-3}$ & 4.63 & -310.0 & 2.03 & 0.0515 \\
\hline P3 & $131.4 \times 10^{-3}$ & $141.5 \times 10^{-3}$ & 8.32 & -310.0 & 3.654 & 0.0928 \\
\hline
\end{tabular}
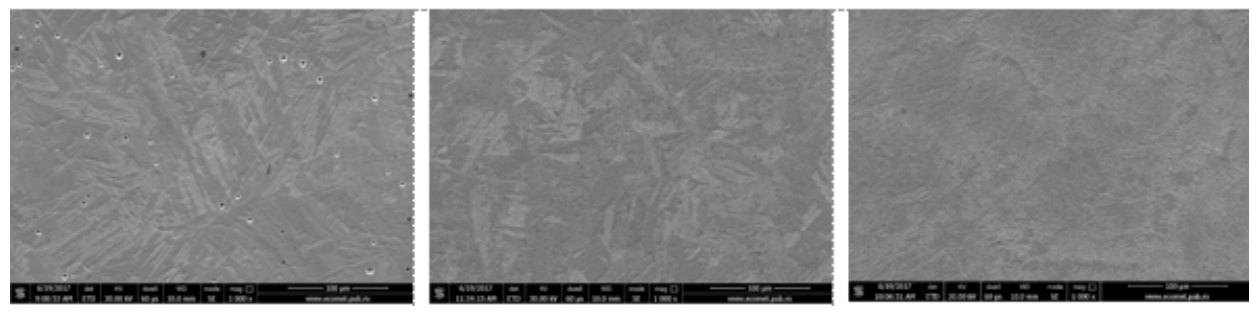

Fig. 3. SEM images of the 3 samples after corrosion in chlorine-free environment 


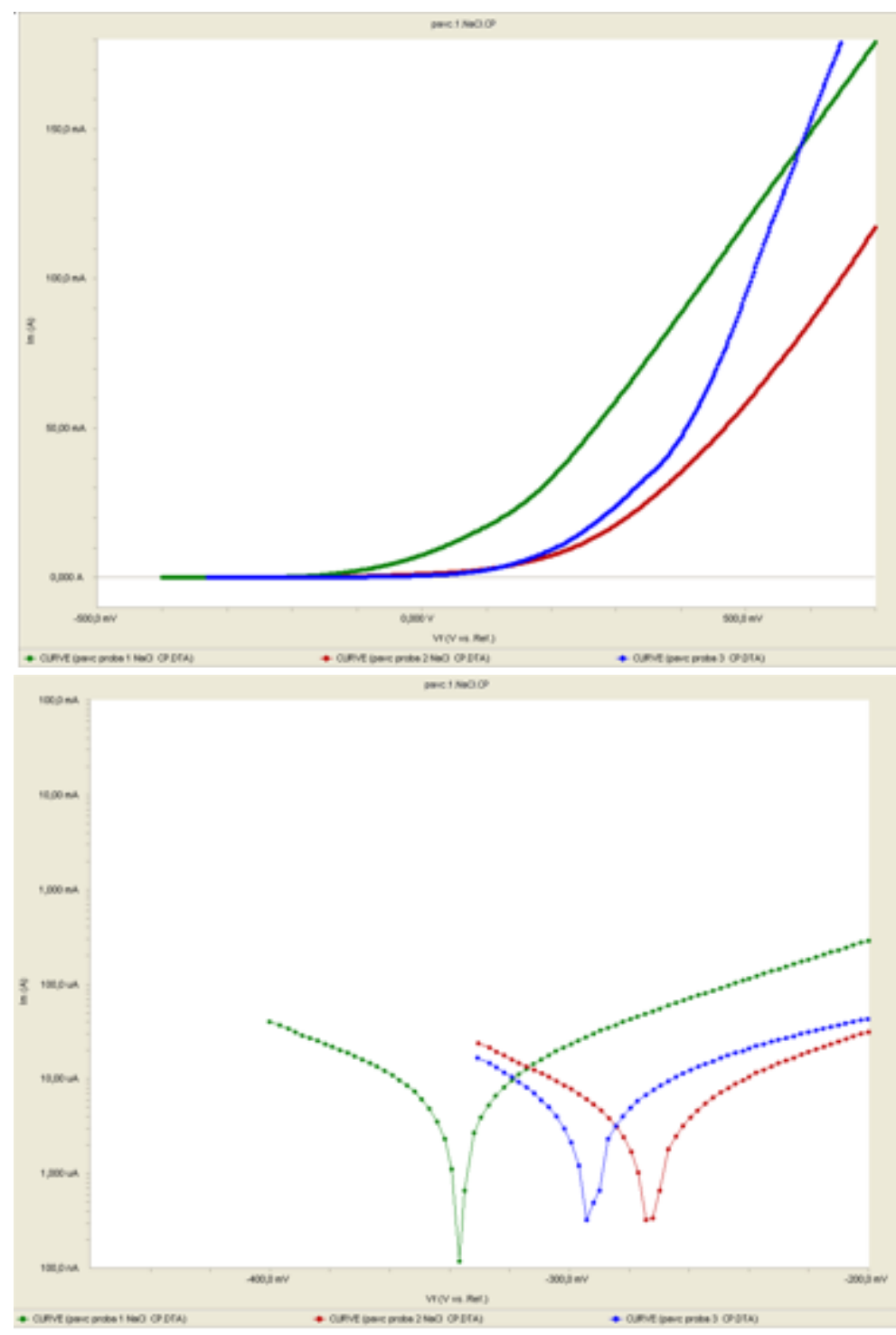

Fig. 4. Anodic polarization curves of the three samples tested in $\mathrm{NaCl} 3 \%$ solution at room temperature with a polarization rate of $1 \mathrm{mV} / \mathrm{s}$.

Fig. 5. Tafel curves for $\mathrm{P} 1, \mathrm{P} 2, \mathrm{P} 3$ steels in $\mathrm{NaCl} 3 \%$ solution.

Table 6

MAIN PARAMETERES OF THE CORROSION PROCESS IN NACL $3 \%$ SOLUTION

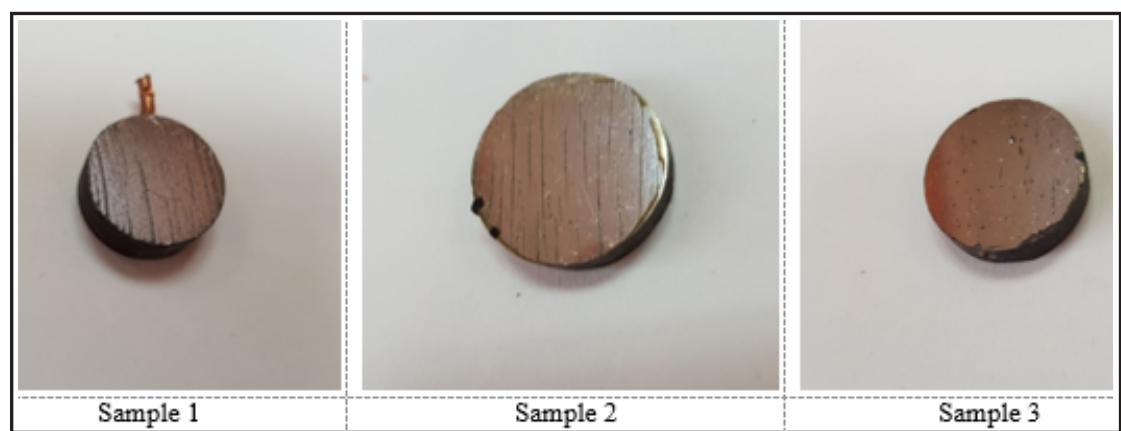

Fig. 6. Macroscopic aspect of the three samples after the electrochemical corrosion test direction on the surface. On SEM microscopy analysis of sample 1 one may observe that the attack started at the interfaces between ferrite crystals and the zones resulted by martensitic decomposition and continued by dislodging large surfaces of the material. Crevices are formed by local oxyde layer distruction and further damage takes an intercrystalline path, between ferrite and martensite grains having different galvanic behavior.

Sample 2 showed the same type of surface attack with material dislocation but without a microscopic selective phase attack.

The increase in $\mathrm{Cr}, \mathrm{Ni}$ and $\mathrm{Mo}$ content significantly enhance the corrosion resistance in the presence of Cl ions, thus the surface of the P3 steel is macroscopically least affected by only very small localized attacks. SEM analysis did not reveal selective phase attacks thus the structure was unchanged.

The very good corrosion behavior of steel $\mathrm{P} 3$ in chlorinefree environments is highlighted when comparing the polarization curves obtained for this material in the presence and absence of chlorine as seen in figure 10 .

Analysis of all corrosion-related results in chlorine-free media for steel P3 correlated with SEM microstructural information reveals very good corrosion resistance properties (very good resistance class) and adequate passivation of the surface. In view of these facts it is 

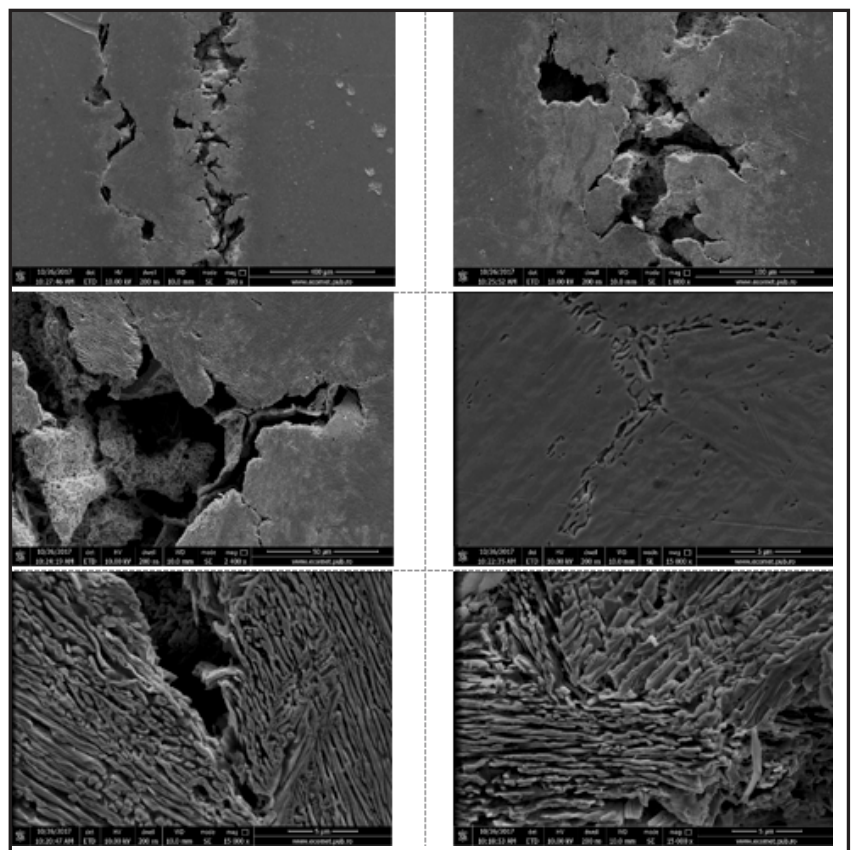

Fig. 7. SEM images showing sample 1 surface aspect at x100, x500, x2400, x15000 magnifications
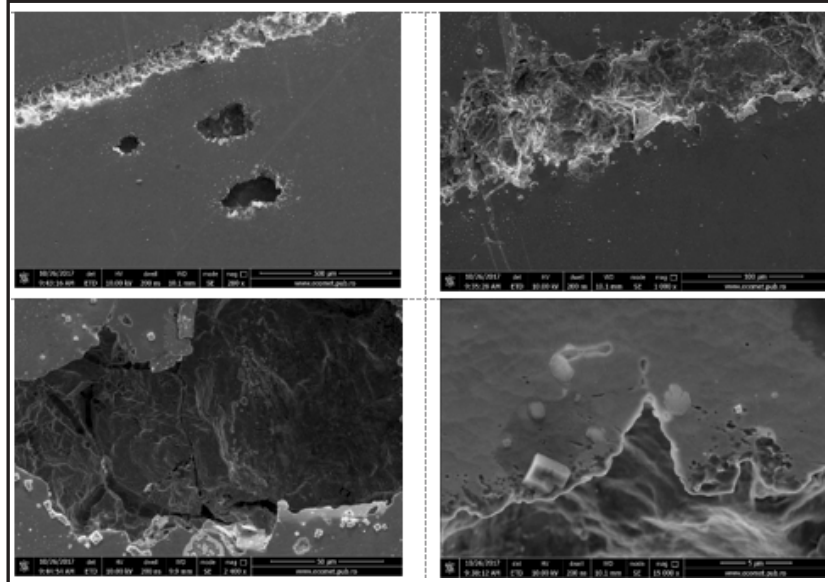

Fig. 8. SEM images showing sample 2 surface aspect at $x 100, x 500$, x2400, x15000 magnifications
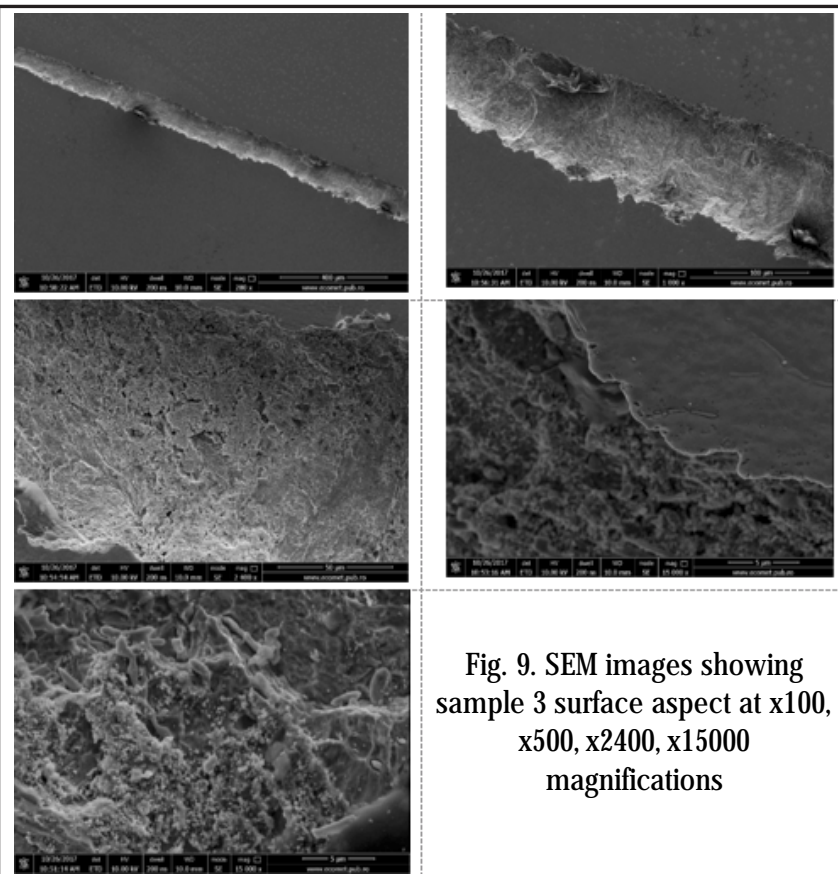

Fig. 9. SEM images showing sample 3 surface aspect at $\times 100$, $x 500, x 2400, x 15000$ magnifications

recommended for use in the construction of hydropower turbine runner blades.

The negative influence of chlorine on the material surface is evident by decreasing the range of passivity by half, therefore the use of this material in saline media is not recommend.

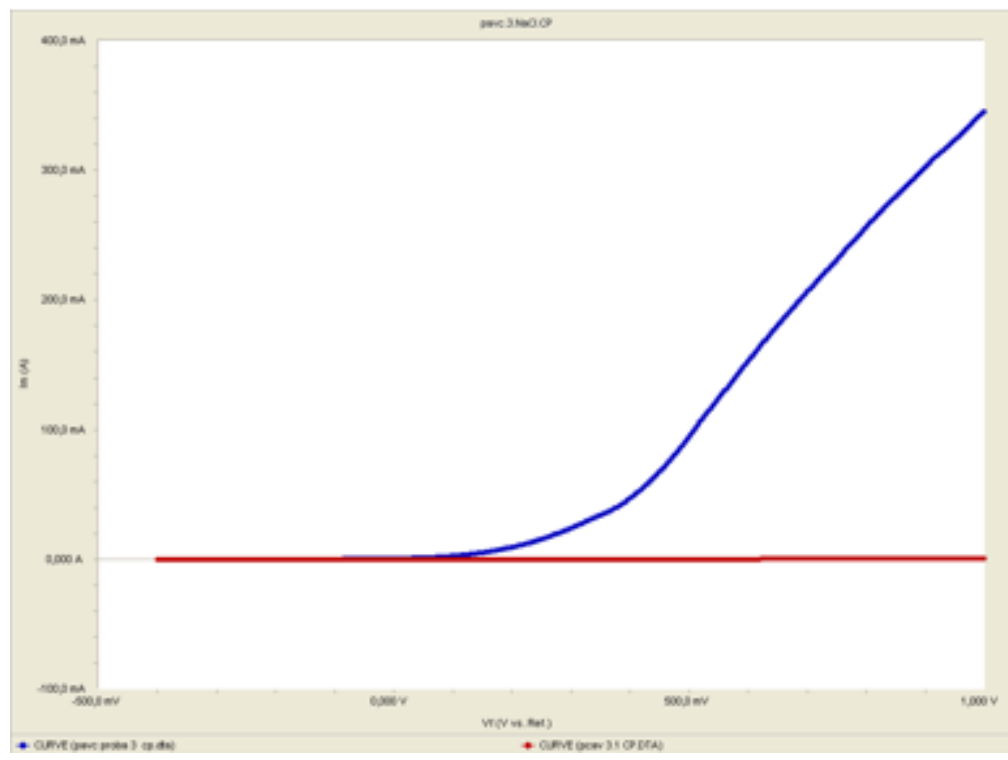

Fig. 10. Polarization curves of steel P3 tested in the presence and absence of chlorine 


\section{Conclusions}

Electrochemical corrosion testing results showed that samples 1 and 2 exhibited large scale attacks of the order of millimeters that followed a preferential direction on the surface.

On scanning electron micrographs of sample 1 one may observe that the attack started at the interface between the ferrite crystals and the zones resulted by martensitic decomposition. It continued further away by dislodging large surfaces of the material. Crevices are formed bylocal oxyde layer distruction and further damage takes an intercrystalline path, between ferrite and martensite grains, due to their different galvanic behavior.

Sample 2 exhibited the same type of surface attack with material dislocations but at a microscopic scale no selective phase attack was observed.

Analyzing the anodic polarization curves, the following aspects emerge: all steels have a passivation tendency in a chlorine-free aqueous medium, specifying however that P3 steel has a more pronounced anodic field as a result of a chromium content below $12 \%$, the theoretical lower limit for stainless steels. The general corrosion behavior of this material is improved by the content of about $10 \% \mathrm{Ni}$ which leads to a mainly martensitic structure in quenched state. Although there is no proper passivation of the surface, it should be noted that the current density values are of the order of i $\mathrm{A} / \mathrm{cm}^{2}$ for all materials including the active dissolution stage (maximum peak of each curve).

Corrosion rates for all samples enframe the three materials in highly and very highly corrosion resistant steels, specifying that in chlorine environments the overall corrosion rate is not an indicator of corrosion resistance performance due to the local depassivation process followed by corrosion pits.
The increase in the $\mathrm{Cr}, \mathrm{Ni}$ and Mo content significantly increases the corrosion resistance in the presence of chlorine ions, so that the surface of the P3 steel sample is macroscopically the least affected, presenting localized attacks of very small size. SEM analysis did not reveal selective phase attacks, the structure being undamaged.

\section{References}

1.SZKLARSKA-SMIALOWSKA, Z., Pitting Corrosion of Metals, National Association of Corrosion Engineers Publisher, Houston (Texas), 1986, p.157.

2.FRANKEL, G., J ELECTROCHEM SOC, 145, Issue 6, 1998, p. 2186.

3.SIDHARTH, A.A.P., DIG J NANOMATER BIOS, 4, no.4, 2009, p. 783.

4.SOHACIU, M., CIUCA, S., SAVASTRU, D., COMAN, G., PREDESCU, A., BERBECARU, A., COTRUT, C., MATEI, E., GHERGHESCU, I.A., PREDESCU, C., OPTOELECTRON ADV MAT, 10, Issue 3-4, 2016, p.259. 5.MATEI, E., PREDESCU, C., BERBECARU, A., PREDESCU, A.M., TRUSCA, R., DIG J NANOMATER BIOS, 6, no. 9, 2011, p. 1701.

6.SCHAEFFLER, A.L., MET PROG, 56, 11, 1949, p. 680.

7.COMAN, G., CIUCA, S., BERBECARU, A.C., PANTILIMON, M.C., SOHACIU, M.G., GRADINARU, C., PREDESCU, C., U POLITEH BUCH SER B, 79, Issue 4, 2017, p. 213.

8.CARTER, J.C.S., METALL TRANS, 1, 1970, p. 1556.

9.ANTOLOVICH, S., SAXENA, A., CHANANI, C.R., METALL TRANS, 5, 1974, p. 627.

10.POPA, M.V., VASILESCU, E., DROB, P., DEMETRESCU, I., VASILESCU, C., IONITA, D., POPA, M.F., Rev. Chim. (Bucharest), 55, no.10, 2004, p.751.

11.POPA, M.V., VASILESCU, E., DROB, P., DEMETRESCU, I., IONITA, D., VASILESCU, C., Rev. Chim. (Bucharest), 54, no.6, 2003, p.503.

Manuscript received:14.01.2019 